\title{
A Novel Polyphase Multipole Square-Wave Permanent Magnet Motor Drive for Electric Vehicles
}

\author{
C. C. Chan, Fellow, IEEE, J. Z. Jiang, G. H. Chen, X. Y. Wang, and \\ K. T. Chau, Member, IEEE
}

\begin{abstract}
A novel high-power-density permanent-magnet (PM) motor drive for electric vehicles (EV's) is proposed. The motor is a polyphase multipole square-wave PM motor, which can be classified as a kind of PM brushless dc motor. The distinct features of the proposed motor as compared to those of the conventional PM brushless dc motor are as follows. First, the multipole magnetic circuit arrangement enables the minimization of the magnetic yoke, resulting in the reduction of motor volume and weight. Second, the coil span is purposely designed to be equal to one slot pitch, thus saving in the amount of copper used. Third, by using a fractional number of slots per pole per phase, the arrangement of the numbers of poles and slots is so unique that the magnetic force between the stator and the rotor at any rotating position is uniform, hence eliminating the cogging torque that usually occurs in PM motors. Finally, the motor can be controlled to operate at a constant torque region and a constant power region with field weakening, thus both high starting torque and high cruising speed can be achieved. Therefore, as the proposed motor drive possesses the distinct advantages of high power density, high efficiency, and superior dynamic performance, it is very suitable for $\mathrm{EV}$ applications. A prototype of a five-phase 22-pole 5-kW motor drive has been designed for an experimental $\mathrm{EV}$.
\end{abstract}

\section{INTRODUCTION}

T HAS been a long-lived objective to develop an advanced motor drive that possesses the dc motor drive advantage of a quality speed control feature, but that eliminates the mechanical commutator and brushes, and possessing the ac motor drive advantages of high reliability, robustness, and being almost free of maintenance for electric vehicle (EV) applications. With the rapid development of power electronics and microelectronics technologies, advancement of control and computational theories, and the advent of new materials, many advanced motor drives have recently been developed [1]-[5]. In recent years, a substantial research program on the development of advanced ac propulsion systems for EV's has been launched and it has been reported that a PM synchronous motor drive, an induction motor drive

Paper IPCSD 94-16, approved by the Industrial Drives Committee of the IEEE Industry Applications Society for presentation at APEC'93. Manuscript released for publication April 25, 1994.

C. C. Chan, J. Z. Jiang, G. H. Chen, and X. Y. Wang are with the Department of Electrical and Electronics Engineering, University of Hong Kong, Pokulam Rd, Hong Kong.

K. T. Chau is with the Department of Electrical Engineering, Hong Kong Polytechnic, Kowloon, Hong Kong.

IEEE Log Number 9404069. incorporating adaptive decoupling control and a switched reluctance motor drive were successfully implemented in a variety of EV's [6].

The multipole structure of a motor leads to reduce the length of end windings so that the utilization factor of copper wires increases and the copper loss decreases. This structure also leads to the shortening of the length of the magnetic circuit, thus reducing both the height of yoke and the volume of the motor. Moreover, the interaction between the square-wave current and the square-wave magnetic field may produce a larger torque than that produced by the interaction between sinusoidal current and the sinusoidal magnetic field [7], [8]. Based on the aforementioned concepts, the idea of a novel polyphase multipole square-wave motor with high power density and high efficiency was introduced. The motor is basically a type of brushless dc motor; therefore, it inherently permits superior dynamic performance. The control strategies used for dc motors can be easily implemented for this motor, such as the dual closed-loop of speed and current feedback.

In this paper, a novel polyphase multipole square-wave PM motor drive is presented. The motor configuration, principle of operation, equivalent model, and design topology are described. By employing the finite element method (FEM), an electromagnetic field analysis is carried out for the design and optimization of the proposed motor. The motor controller adopts a dual closed-loop control with a hysteresis current scheme. Simulation and experimental results of the motor drive verify its suitability for EV applications.

\section{Novel Polyphase Multlpole PM Motor}

\section{A. Motor Configuration}

The schematic configuration of the proposed motor is shown in Fig. 1, which is a five-phase 22-pole square-wave PM motor. The motor has 20 slots, where two sides of a coil are located in two adjacent slots, namely slot 1 and slot 2 , while another coil of the same phase is located in slot 11 and slot 12 . These two coils are connected in series. The other phase windings can be arranged in the same way. The winding connection diagram is shown in Fig. 2. The rotor consists of 22 pieces of PM to form 22 poles. Two adjacent poles make up a pole pair. Total 


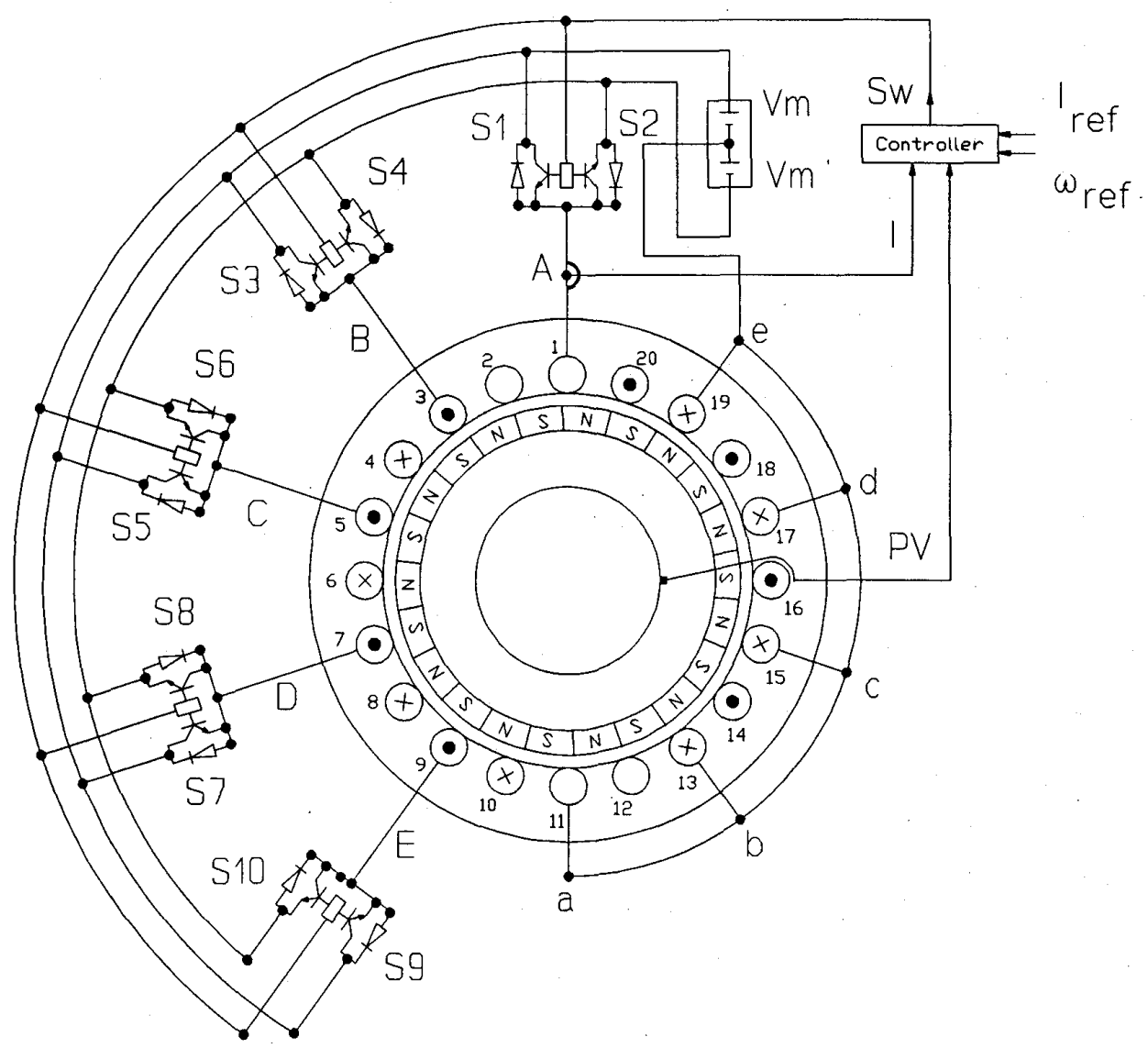

Fig. 1. Five-phase 22-pole PM motor.

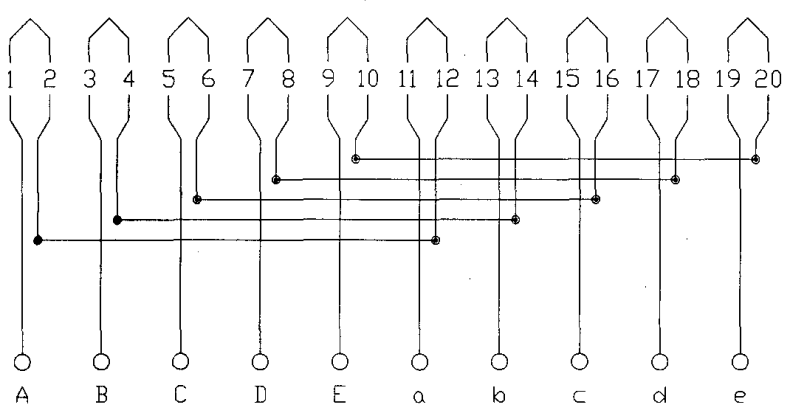

Fig. 2. Winding connection diagram.

number of pole pairs is 11 . This indicates that the slot pitch of two adjacent slots is $11 / 10$ pole pitch, and the phase pitch of two adjacent phases is $11 / 5$ pole pitch. By using this arrangement of a fractional number of slots per pole per phase, the magnetic force between the stator and the rotor at any rotating position is uniform, hence eliminating the cogging torque that usually occurs in PM motors.

\section{B. Principle of Operation}

When all currents in slots under $S$-poles flow toward the reader and all currents in slots under $\mathrm{N}$-poles flow away from the reader, as illustrated in Fig. 1, the direction of torque produced on the rotor will be counterclockwise, and vice versa. According to this coordination between stator slots and rotor poles, at any moment, there are four phase windings in the conducting state and one phase winding in the nonconducting state. For example, at the moment when the rotor position is as shown in Fig. 1, phase $A$ is in a nonconducting state. Subsequently, the rotor rotates $18^{\circ}$ phase $B$ will become nonconducting, and so on. As shown in Fig. 3, each phase winding will conduct $144^{\circ}$ over a half-cycle, and the phase shift between adjacent phases is $36^{\circ}$.

The conducting state depends on the feedback signal PV from a rotor position sensor, as shown in Fig. 4, which consists of optodevices mounted on the motor frame (end bracket) and a toothed disk mounted on the rotor shaft. The signal PV possesses two functions: first, it senses the rotor position to determine the conducting state of each winding; second, it provides a speed feedback signal to the controller. As previously mentioned, this motor belongs to a type of brushless dc motor; the commutation process is executed by the rotor position sensor and electronic switches. The direction of rotation is determined by the commutating logic, and the commutating frequency adapts to the motor speed. Like a dc motor, the speed control of 


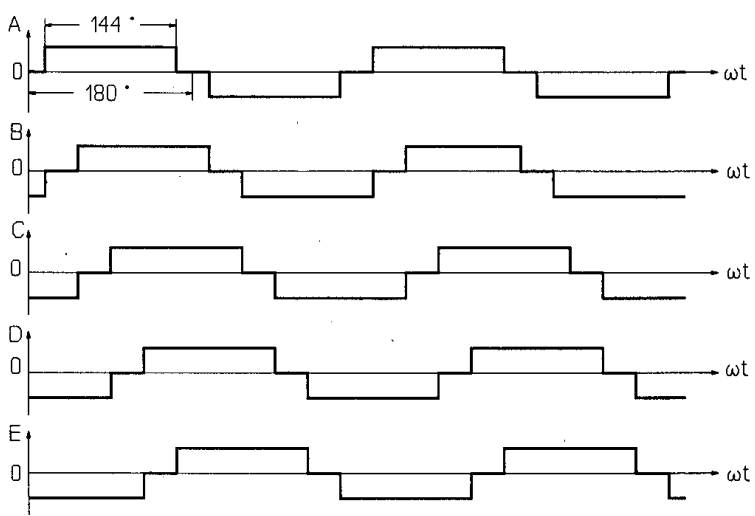

Fig. 3. Voltage waveforms of five-phase windings.

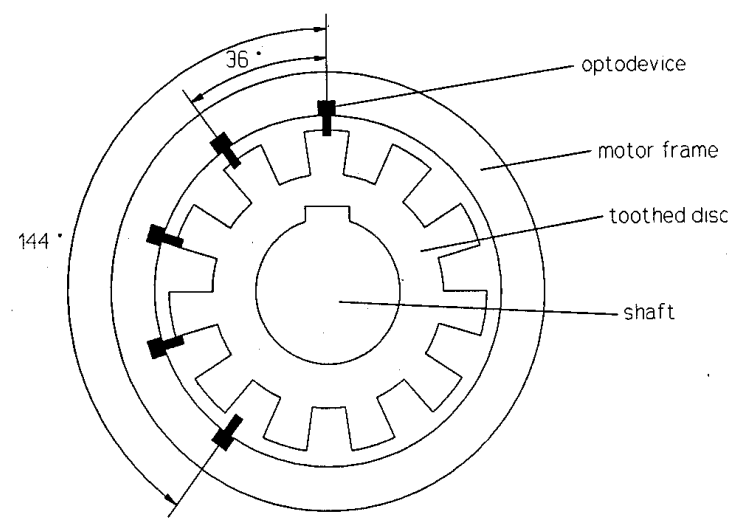

Fig. 4. Rotor-position sensor.

this motor can be easily implemented by regulating the applied voltage.

\section{Equivalent Model}

Consider that a polyphase multipole square-wave motor has $m$-phase windings on the stator, $p$ pairs of PM poles on the rotor, and no damper windings on the pole faces. Due to the high resistivity of the magnet, induced current in the rotor can be neglected. Assuming that the resistance of each phase winding is the same, the voltage equation set for $m$ phases is

$$
\begin{aligned}
{\left[\begin{array}{c}
v_{1} \\
v_{2} \\
\vdots \\
v_{m}
\end{array}\right]=\left[\begin{array}{cccc}
R & & & \\
& R & & \\
& & \ddots & \\
& & & R
\end{array}\right]\left[\begin{array}{c}
i_{1} \\
i_{2} \\
\vdots \\
i_{m}
\end{array}\right] } \\
+p\left[\begin{array}{cccc}
L_{11} & L_{12} & \cdots & L_{1 m} \\
L_{21} & L_{22} & \cdots & L_{2 m} \\
\vdots & \vdots & \cdots & \vdots \\
L_{m 1} & L_{m 2} & \cdots & L_{m m}
\end{array}\right]\left[\begin{array}{c}
i_{1} \\
i_{2} \\
\vdots \\
i_{m}
\end{array}\right]+\left[\begin{array}{c}
e_{1} \\
e_{2} \\
\vdots \\
e_{m}
\end{array}\right]
\end{aligned}
$$

where $v, i$ and $e$ are the per-phase voltage, current, and back EMF. Assuming further that the rotor inductances associated with different rotor angular positions are identical, thus

$$
\begin{gathered}
L_{11}=L_{22}=\cdots=L_{m m}=L \\
L_{12}=L_{21}=M_{12} \\
\vdots \\
L_{1 m}=L_{m 1}=M_{1 m} .
\end{gathered}
$$

Due to the coil span being designed to be equal to the slot pitch, the phase flux paths are independent, hence the mutual inductances $M$ of phase windings are negligible:

$$
M_{12}=\cdots=M_{1 m}=0
$$

so that (1) can be written as

$$
\begin{aligned}
{\left[\begin{array}{c}
v_{1} \\
v_{2} \\
\vdots \\
v_{m}
\end{array}\right]=\left[\begin{array}{lllll}
R & & & \\
& R & & \\
& & \ddots & \\
& & & R
\end{array}\right]\left[\begin{array}{c}
i_{1} \\
i_{2} \\
\vdots \\
i_{m}
\end{array}\right] } \\
+p\left[\begin{array}{llll}
L & & \\
& L & & \\
& & \ddots & \\
& & & L
\end{array}\right]\left[\begin{array}{c}
i_{1} \\
i_{2} \\
\vdots \\
i_{m}
\end{array}\right]+\left[\begin{array}{c}
e_{1} \\
e_{2} \\
\vdots \\
e_{m}
\end{array}\right] .
\end{aligned}
$$

Since the electromagnetic torque equations of motion are given by

$$
\begin{gathered}
T_{e}=\left(e_{1} i_{1}+e_{2} i_{2}+\cdots+e_{m} i_{m}\right) / \omega \\
T_{e}-T_{L}-B \omega=J p \omega
\end{gathered}
$$

the state-space equations with state-space variables of $i_{1}, i_{2}, \cdots, i_{m}$, and $\omega$ can be rewritten as

$$
\begin{aligned}
& p\left[\begin{array}{c}
i_{1} \\
i_{2} \\
\vdots \\
i_{m} \\
\omega
\end{array}\right]=\left[\begin{array}{ccccc}
1 / L & & & & \\
& 1 / L & & & \\
& & \ddots & & \\
& & & 1 / L & \\
& & & & 1 / J
\end{array}\right] \\
& \left\{\left[\begin{array}{c}
v_{1} \\
v_{2} \\
\vdots \\
v_{m} \\
T_{e}
\end{array}\right]-\left[\begin{array}{lllll}
R & & & & \\
& R & & & \\
& & \ddots & & \\
& & & R & \\
& & & & B
\end{array}\right]\left[\begin{array}{c}
i_{1} \\
i_{2} \\
\vdots \\
i_{m} \\
\omega
\end{array}\right]+\left[\begin{array}{c}
e_{1} \\
e_{2} \\
\vdots \\
e_{m} \\
T_{L}
\end{array}\right]\right\} \text {. }
\end{aligned}
$$

The back EMF and current waveforms of a five-phase square-wave motor are shown in Fig. 5. For producing a rippleless steady-state torque, the currents $i_{1}, i_{2}, \cdots, i_{m}$ are rectangular in shape. This means that the conventional coordinate transformation method can no longer be directly applicable. Therefore, these phase currents are 


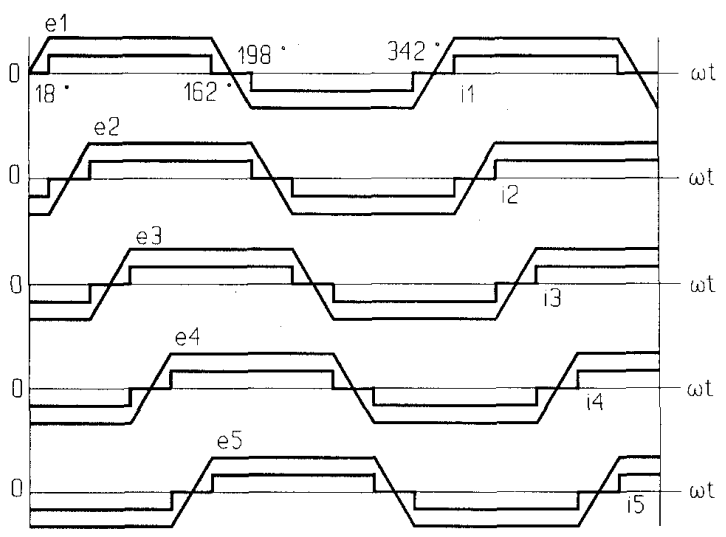

Fig. 5. Back EMF and current waveforms.

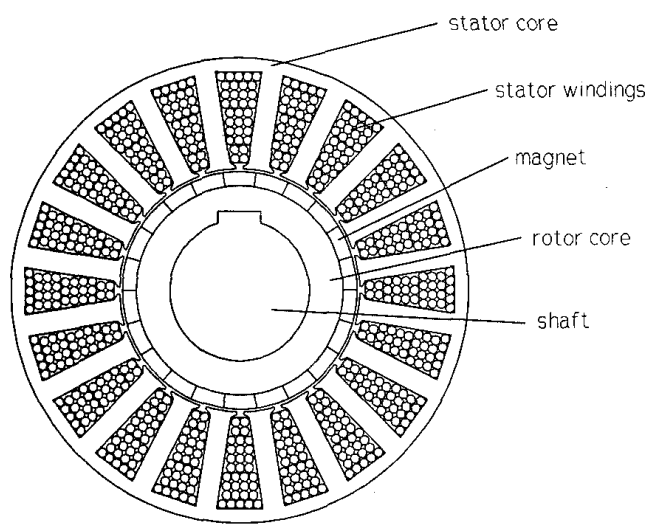

Fig. 6. Typical inner rotor construction of the motor.

treated as state-space variables and the state-space equations are adopted.

The equivalent model presented in this section will be used for the simulation calculation described in Section V.

\section{Design Topology}

Another special feature of the proposed motor is that the design topology can be varied. The conventional inner rotor motor shown in Fig. 6 can be used for general-purpose applications, while the outer rotor motor shown in Fig. 7 can be used as a wheel or drum motor. Since the motor may be designed as a low-speed high-torque motor, it can be used as a direct drive without gear reduction for EV's.

\section{ElectromagnetiC-Field ANALysis}

The design and optimization process of the motor can be summarized as follows: try;

- initial design the motor configuration and geome-

- analyze the motor parameters and performances using an FEM; and

- modify the motor geometry iteratively.

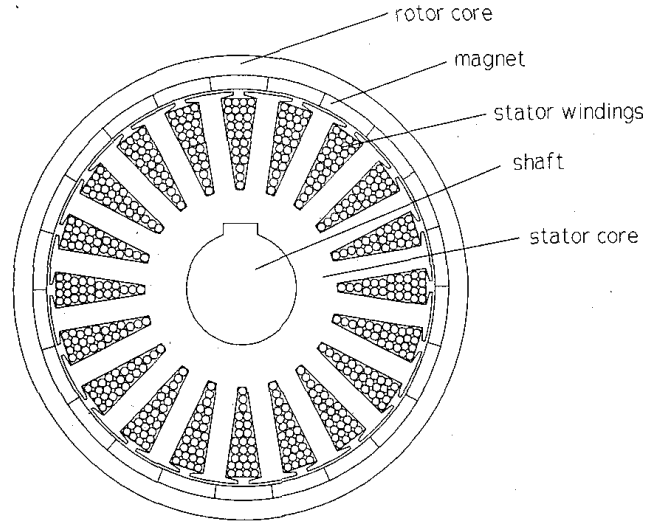

Fig. 7. Typical outer rotor construction of the motor.

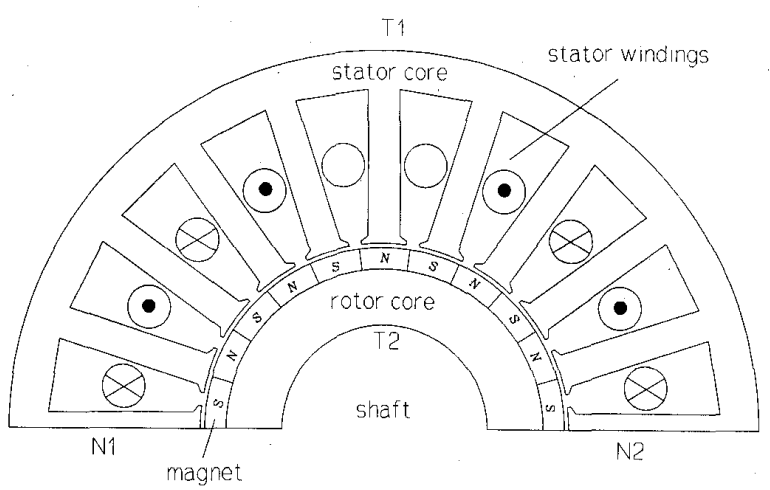

Fig. 8. Region of interest for finite element analysis.

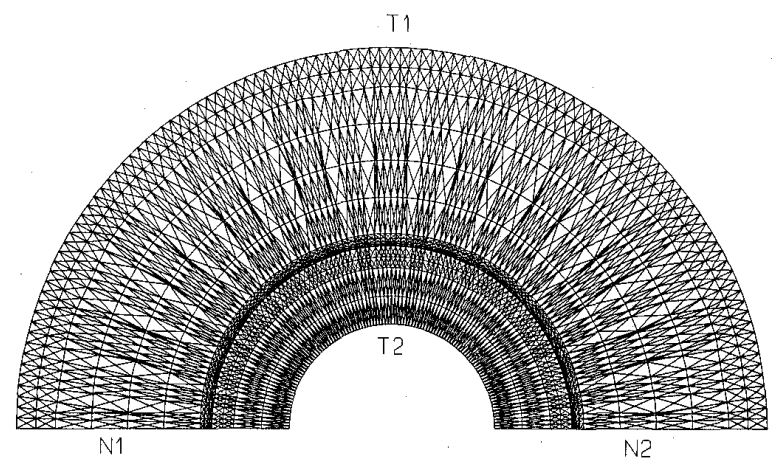

Fig. 9. Generated mesh for finite element analysis.

\section{A. Finite Element Model}

Due to the semiperiodic motor configuration, the region of interest for finite element analysis is shown in Fig. 8. In order to obtain accurate results, the numbers of nodes and elements should be sufficient while the distribution and shape of the triangular elements should be appropriate. Fig. 9 shows the finite element mesh of this motor. 


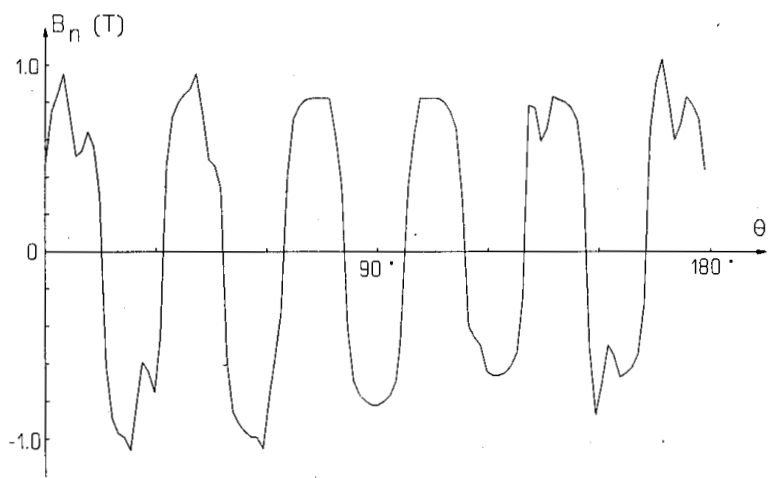

Fig. 10. Normal component of airgap flux density.

The Maxwell's equation of the model can be written as

$$
\nu \frac{\partial A}{\partial x^{2}}+\nu \frac{\partial A}{\partial y^{2}}=-J_{z}+\nu \frac{\partial M_{y}}{\partial x}-\nu \frac{\partial M_{x}}{\partial y} .
$$

The flux density distribution $B$ can be deduced from the vector potential $A$

$$
B=\operatorname{rot} A
$$

or simply by using

$$
B_{x}=\frac{\partial A}{\partial y} \quad B_{y}=-\frac{\partial A}{\partial x} .
$$

The boundary conditions of the model are

$$
\left.A\right|_{T 1}=\left.A\right|_{T 2}=\left.0 \quad A\right|_{N 1}=-\left.A\right|_{N 2} .
$$

Moreover, the electromagnetic force can be calculated by using the Maxwell stress-tensor method. The components of force on a line parallel to the $x$ axis are expressed as

$$
f_{x}=\frac{B_{x} B_{y}}{\mu_{0}} \quad f_{y}=\frac{1}{2 \mu_{0}}\left(B_{y}^{2}-B_{x}^{2}\right)
$$

and the components of force on a line parallel to the $y$ axis are expressed as

$$
f_{x}=\frac{1}{2 \mu_{0}}\left(B_{x}^{2}-B_{y}^{2}\right) \quad f_{y}=\frac{B_{x} B_{y}}{\mu_{0}} .
$$

\section{B. Results of Analysis}

Having obtained the magnetic flux density distributions, it can be found that the flux distribution under no-load conditions is symmetrical, while it is unsymmetrical under full-load conditions due to the effect of armature reaction. It is well known that the airgap flux distribution is essential because the energy conversion is processed through the airgap. Thus, the normal and tangential components of the flux density and force density along the airgap periphery under full-load conditions are illustrated, respectively, in Figs. 10-13.

Based on these results, the motor geometry can be adjusted as desired to achieve optimization. Moreover, as shown in Fig. 14, it can be found that the commutation

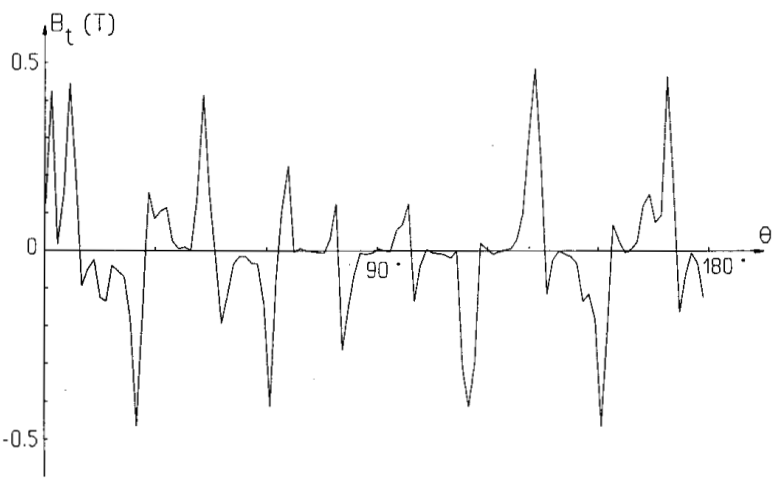

Fig. 11. Tangential component of airgap flux density.

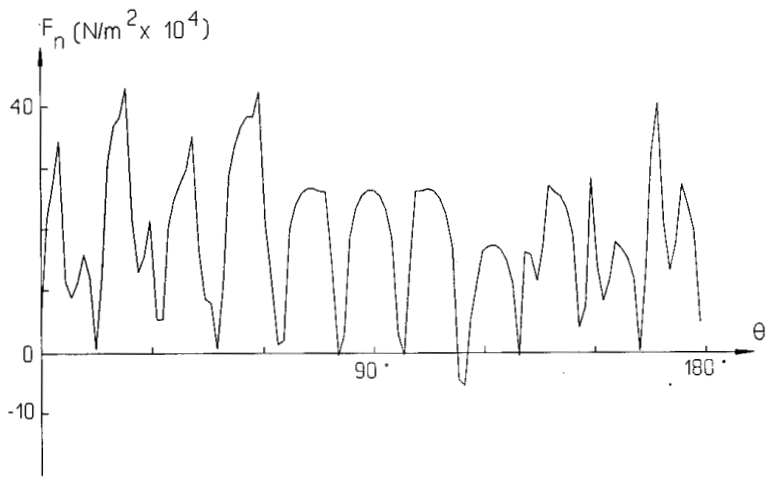

Fig. 12. Normal component of airgap force density.

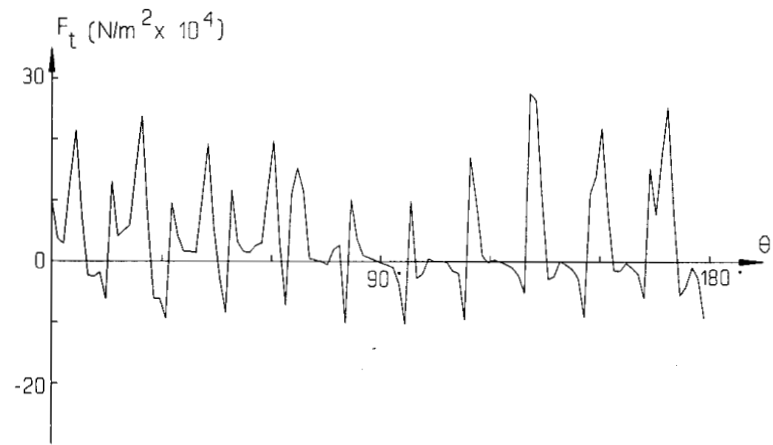

Fig. 13. Tangential component of airgap force density.

causes the torque pulsation. In fact, besides the commutation, another kind of torque pulsation is caused by the current pulsation associated with the hysteresis current control scheme, which will be discussed later. As shown in Fig. 15, it can also be found that the total tangential force under no-load conditions is very small; hence, the cogging torque that usually occurs in PM motors is eliminated for the proposed motor.

\section{CONTROL SYSTEM}

The proposed motor is basically a brushless dc motor, therefore the control technique used for dc motors can be 


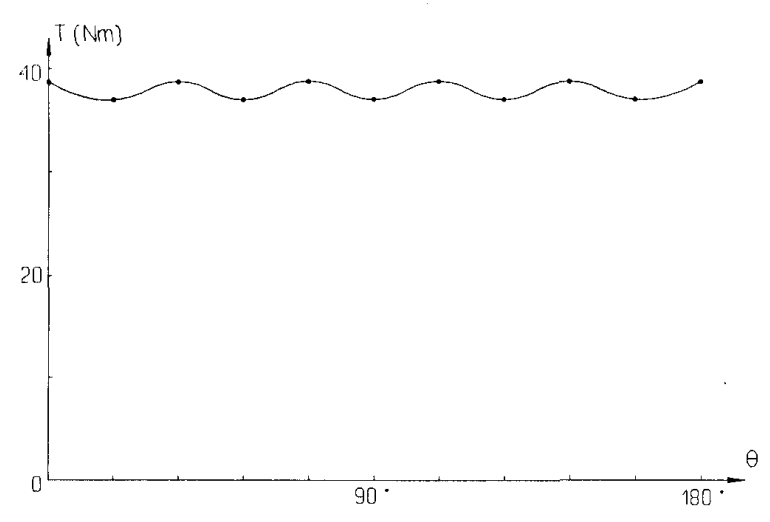

Fig. 14. Steady-state torque versus rotor position.

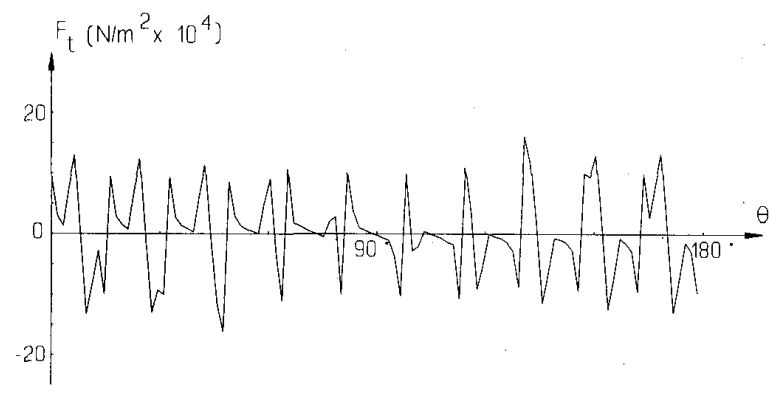

Fig. 15. No-load tangential force density.

easily implemented for this motor, such as the dual closed-loop of the speed feedback and current feedback control system. As compared with the vector control of induction motors, the control is much simpler because there is no vector transformation. Fig. 16 shows the block diagram of the control system for the proposed motor, and the control process can be explained by Fig. 17. When the speed reference signal $\omega_{\text {ref }}$ is set from 0 to 1 , the motor begins starting and the speed feedback is increasing gradually. The difference between $\omega_{\text {ref }}$ and speed feedback from SF is inputted into the speed regulator SR. The amplified output $I_{\text {ref }}$ serves as a reference for the inner current loop. The phase current feedback from CF is compared with $I_{\text {ref }}$, and their difference is inputted into the current regulator CR. The output of CR and the signal from the rotor position sensor are combined through a logic circuit to form the firing signal of power switching devices. The current control in each phase can be implemented by using the hysteresis loop (current band-band) method. A proportional-integral (PI) regulator is used as the speed control of the proposed motor.

\section{Simulation AND EXPERIMENTAL RESULTS}

Based on the equivalent model given by (1)-(8), as well as the block diagram illustrated in Fig. 16, the simulation calculation can be performed. Fig. 18 shows the current and torque waveforms at high switching frequency. It can be found that the current ripple is very small and the

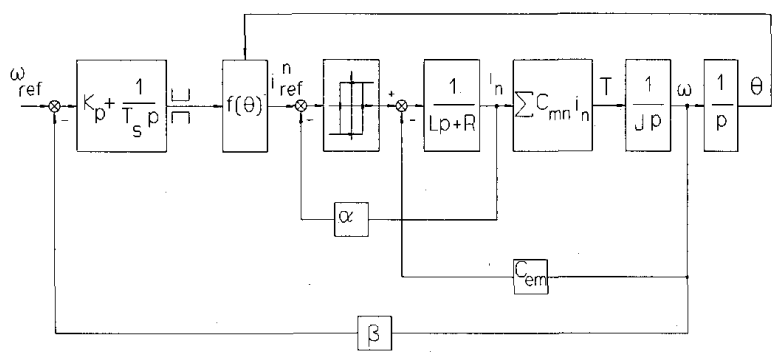

Fig. 16. Block diagram of control system.

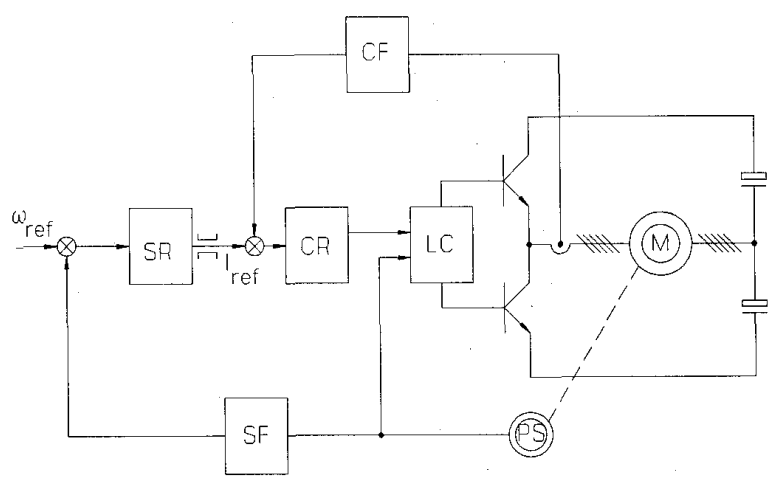

Fig. 17. Dual closed-loop control process.

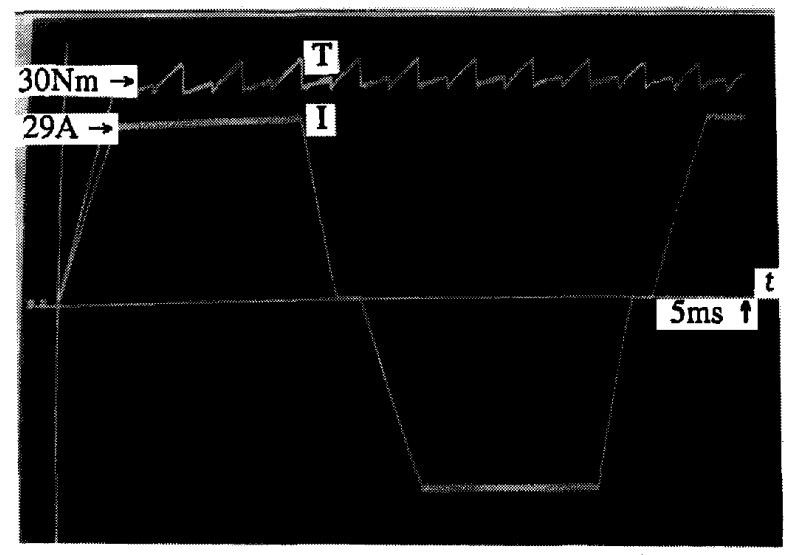

Fig. 18. Current ripple and torque pulsation at high switching frequency.

torque pulsation is mainly due to the commutating current. On the contrary, as shown in Fig. 19, the current ripple is relatively high at low switching frequency and the torque pulsation is due to the commutating current and hysterésis current ripple. However, it can be seen that the torque pulsation of this motor is small.

Fig. 20 shows the steady-state torque-speed characteristics obtained from laboratory experiments, while Fig. 21 shows the torque, speed and current transients under a sudden load change obtained from simulation calculations.' 
TABLE I

TECHNICAL DATA FOR THE MOTOR

Stator

Outer diameter:

Inner diameter:

Length of core:

Number of slots:

Number of poles:

Slot width:

Slot height:

Winding type:

Number of coils:

Turns per coil:

Conductor size:

Slot pitch:

Resistance $\left(75^{\circ}\right)$

Rotor

Outer diameter:

Inner diameter:

Magnet height:

Magnet material:

Copper weight:

Magnet weight:

Active iron weight:

Magnet remanence:

Magnet coercive force:
$175 \mathrm{~mm}$

$86 \mathrm{~mm}$

$100 \mathrm{~mm}$

20

22

$7.4 \mathrm{~mm}$

$36 \mathrm{~mm}$

Single layer

10

26

$7 \times 1.06 \mathrm{~mm}$

$1 \sim 2$

$0.054 \Omega$

$84 \mathrm{~mm}$

$48 \mathrm{~mm}$

$5 \mathrm{~mm}$

Nd-Fe-B

$4.10 \mathrm{~kg}$

$0.93 \mathrm{~kg}$

$8.05 \mathrm{~kg}$

$1.1 \mathrm{~T}$

$676.4 \mathrm{kA} / \mathrm{m}$

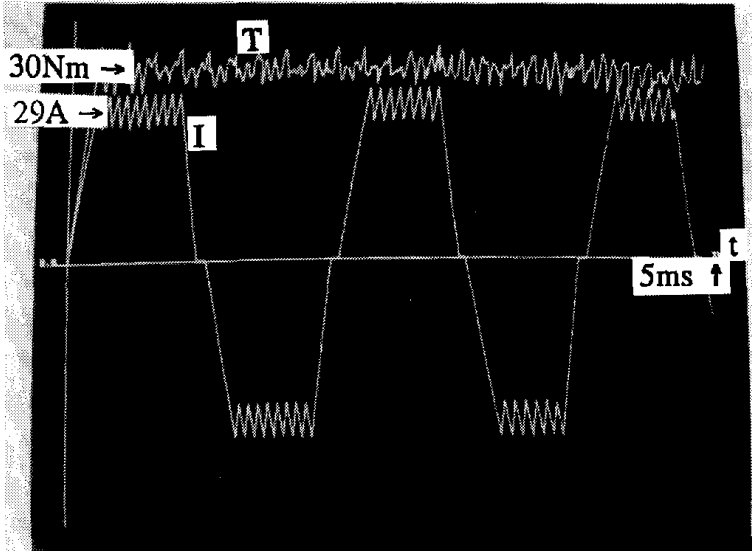

Fig. 19. Current ripple and torque pulsation at low switching frequency.

\section{EV ApPLICATIONS}

A prototype of a five-phase 22-pole 5-kW motor drive has been designed for an experimental EV, shown in Fig. 22. The technical data of the motor and the specifications of the experimental EV are listed in Tables I and II, respectively.

\section{CONCLUSION}

A novel PM brushless variable-speed motor has been designed, built, tested, and implemented for an EV. The motor possesses the advantages of both dc and ac motors: it has superior control performance like a dc motor; but it has superior robust construction and is almost mainte-

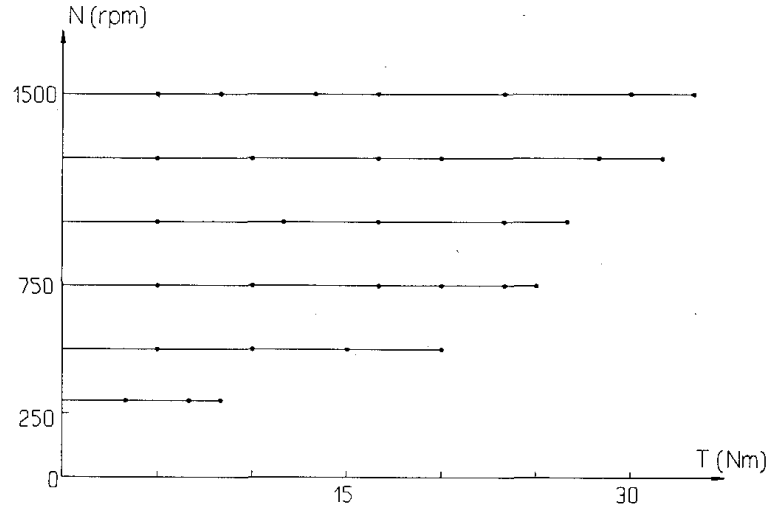

Fig. 20.

nance free, like an ac motor. Moreover, by the unique arrangement of the rotor magnets, stator slots, and stator winding, the motor is able to achieve a high power density, high efficiency, and no cogging torque. The electromagnetic-field analysis of the motor is carried out by using an FEM. By using the state-space model of the motor as well as the real-time models of the speed controller, current controller, and inverter switches, the current ripple and torque pulsation can be clearly investigated. The steady-state and dynamic performances of the motor are used to verify the theoretical predictions. The motor possesses a high potentiality for EV applications.

\section{REFERENCES}

[1] B. K. Bose, "Power electronics - An emerging technology," IEEE Trans. Industrial Electron., vol. 36, pp 403-412, Aug. 1989. 
TABLE II

SPECIFICATIONS FOR THE EV

$\begin{array}{ll}\text { Gross weight: } & 403 \mathrm{~kg} \\ \text { Normal payload: } & 200 \mathrm{~kg} \\ \text { Top speed: } & 30 \mathrm{~km} / \mathrm{h} \\ \text { Gradeability: } & 15^{\circ} \\ \text { Acceleration: } & 8 \mathrm{~s}(0-20 \mathrm{~km} / \mathrm{h}) \\ \text { Range at } 20 \mathrm{~km} / \mathrm{h}: & 70 \mathrm{~km}\end{array}$

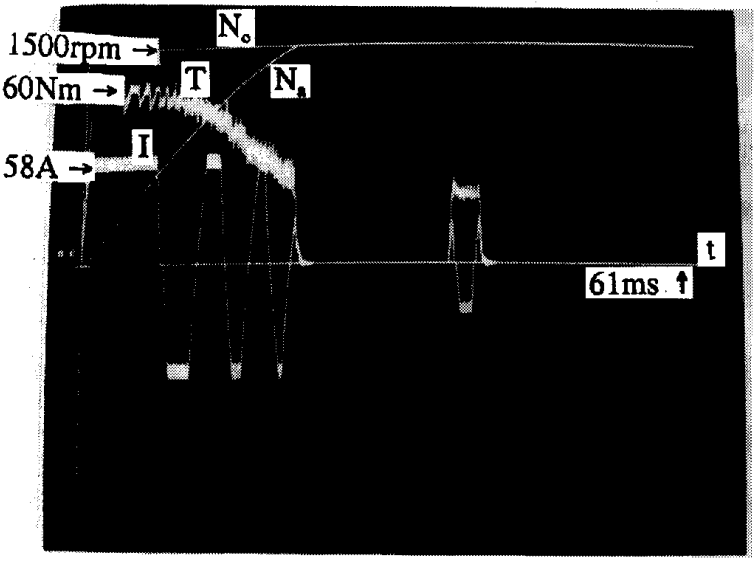

Fig. 21. Dynamic performance under sudden load change.

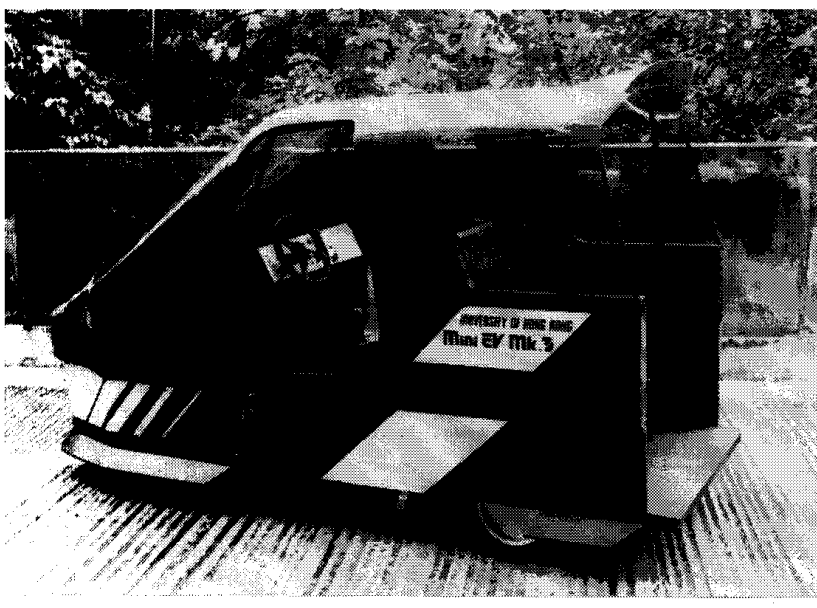

Fig. 22. Experimental EV.

[2] T. A. Lipo, "Recent progress in the development of solid-state ac motor drives," IEEE Trans. Power Electron., vol. 3, pp. 105-117, Apr. 1988.

[3] P. C. Sen, "Electric motor drives and control-Past, present and future," IEEE Trans. Industrial Electron., vol. 37, pp. 562-575, Dec. 1990.

[4] S. D. Sudhoff and P. C. Krause, "Operating model of the brushless dc motor with $120^{\circ}$ inverter," IEEE Trans. Energy Conversion, vol. 5, pp. 558-564, Sept. 1990.

[5] P. Pillay and R. Krishnan, "Modeling, simulation and analysis of permanent-magnet motor drives-Part 2: The brushless dc motor drive," IEEE Trans. Industry Applicat., vol. 25, pp. 274-279, Mar./Apr. 1989

[6] C. C. Chan and K. T. Chau, "Advanced ac propulsion systems for electric vehicles," in Proc. Int. Symp. Automotive Technol., Automat., Florence, Italy, 1991, pp. 119-125.
[7] H. Weh and U. Schröder, "Static inverter concepts for multiphase reluctance machines with reduced armature reaction and improved power density," in Proc. Euro. Power Electron. Conf., Brussels, Belgium, 1985, pp. 1147-1152.

[8] T. M. Jahns, "Torque production in permanent-magnet synchronous motor drivers with rectangular current excitation," IEEE Trans. Industry Applicat., vol. 20, pp. 803-813, Sept./Oct. 1984.

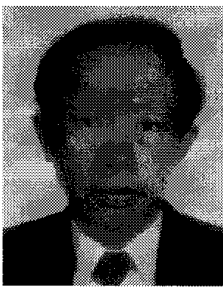

C. C. Chan (F'92) was born in 1937 in Indonesia He obtained B.Sc., M.Sc., Ph.D., and Honorary D.Sc. all in Electrical Engineering from China University of Mining \& Technology in 1957, Tsing Hua University in 1959, University of Hong Kong in 1980 and Odessa Polytechnic University in 1992, respectively. He began his professional electrical engineering career in 1959. He has been working 11 years in industry and 24 years in academia; he is presently the endowed Honda Professor of Engineering and Director of the International Research Center for Electric Vehicles, University of Hong Kong. He was a visiting professor at several wellknown universities, including the University of California Berkeley. He serves as Consultant to several organizations in Hong Kong and the United States.

Prof. Chan is Fellow of the IEE and HKIE, Chairman of IEEE Technical Committee, and is listed in "International Leaders of Achievement, "Men of Achievement," "Who's Who in Australasian and the Far East," and so on. He is the cofounder of the World Electric Vehicle Association. His research interests include advanced motor drives and electric vehicles. He has published four books and over 80 technical papers on electrical engineering.

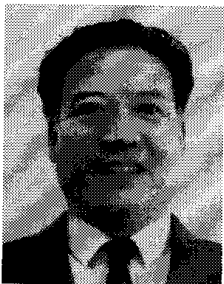

J. Z. Jiang was born in Jiangsu, China, on October 11,1939 . He received the B.E.E and M.E.E degrees from Shanghai Jiao-Tong University in 1962 and 1965, respectively, and the Dr.-Ing. degree from the Technical University of Braunschweig, Germany, in 1988.

$\mathrm{He}$ is a Professor with the Department of Electrical Engineering, Shanghai University of Technology. His research interests are in highperformance variable-speed drives, electric machine design, numerical analysis of electromagnetic fields in electric machinery, and the dynamic modeling of machines and their associated power electronics. He has published about 25 papers and has two patents issued in these fields.

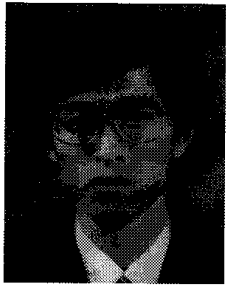

G. H. Chen was born in Shanghai, China, in 1963. He received B.Sc. Eng. degree in electrica engineering from Shanghai University of Technology in 1985 .

He has been with Nanyang Electric Machine Works and Shanghai University of Technology His research interests include CAD of electric machines, numerical analysis of electromagnetic fields in electrical machinery, electric machine controllers, and electric vehicles. He has pubsued in these field. 


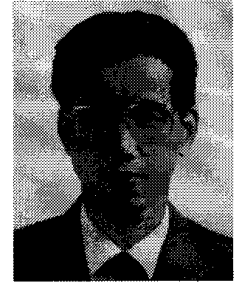

X. Y. Wang was born in Zhejiang, China, in 1942. He obtained his Diploma and B.Sc. degree all in electrical engineering from Shanghai Electric Machines School in 1962 and Shanghai University of Technology in 1968, respectively. He began his professional career in 1962, devoted to the control and testing of linear motors, high-speed motors, and reluctance motors.

$\mathrm{He}$ is now an engineer with the Department of Electrical Engineering, Shanghai University of Technology. His research interests include power electronics and the control systems of electric machines. $\mathrm{He}$ has published several papers and has two patents issued in these field.

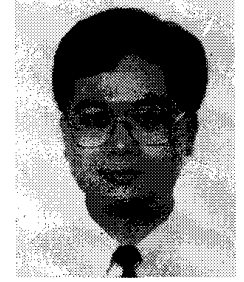

K. T. Chau (M'89) received the first-class honours B.Sc.(Eng.), M.Phil. and Ph.D. degrees, all in electrical and electronic engineering, from the University of Hong Kong in 1988, 1991, and 1993, respectively.

Since 1990, he has been with Hong Kong Polytechnic, where he is currently a Lecturer with the Department of Electrical Engineering. His research interests include power electronics, circuits and systems, and electric drives. He has published over 30 refereed technical papers and several industrial reports.

Dr. Chau was the recipient of the Sir Edward Youde Memorial Fellowships for 1988-1990. 